\title{
Ca'granda
}

\section{edifioio de viviendas}

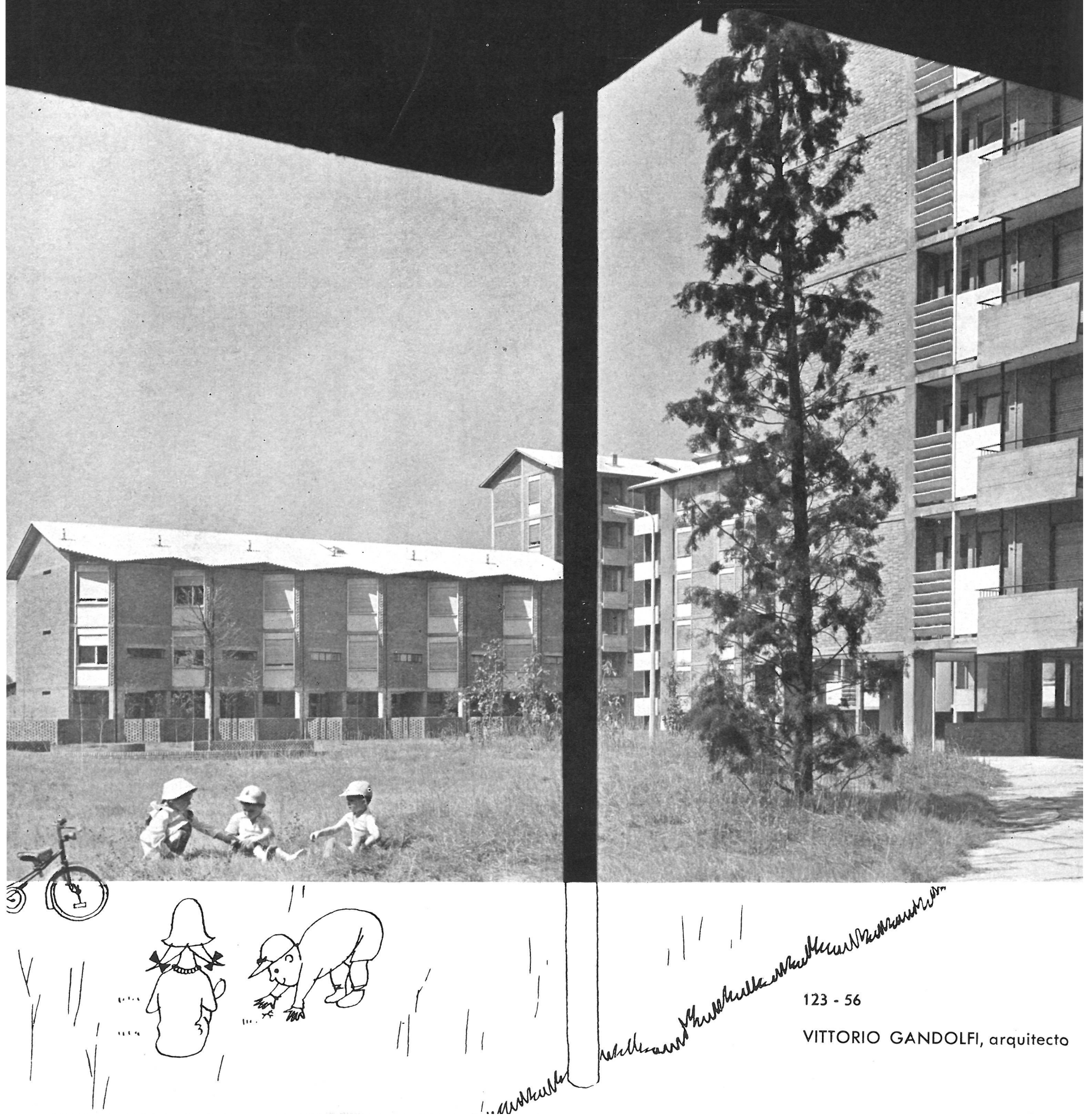




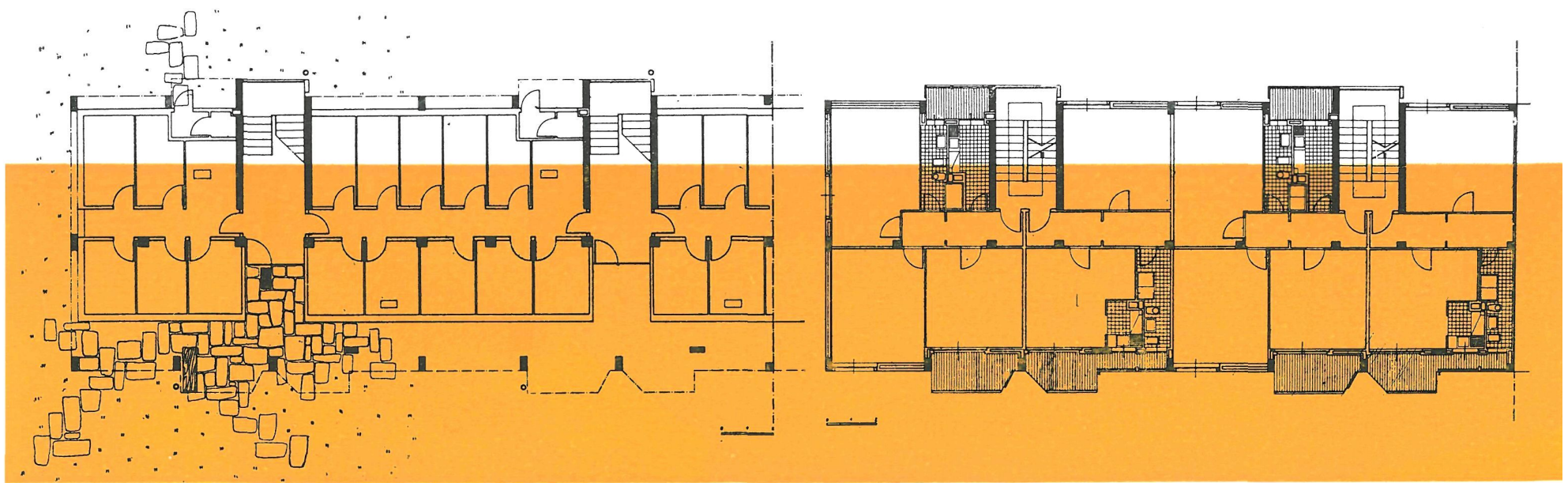

Con el nombre de "Ca'Granda" se ha querido designar el distrito, capaz de 6.000 habitantes, que el Ayuntamiento de Milán está construyendo, y en parte ha construído ya, en la zona detrás de las calles Fulvio Testi y Ospedale Maggiore; es decir, en el sector norte de la ciudad correspondiente a la dirección de mayor impulso del desarrollo urbanístico de lo habitado.

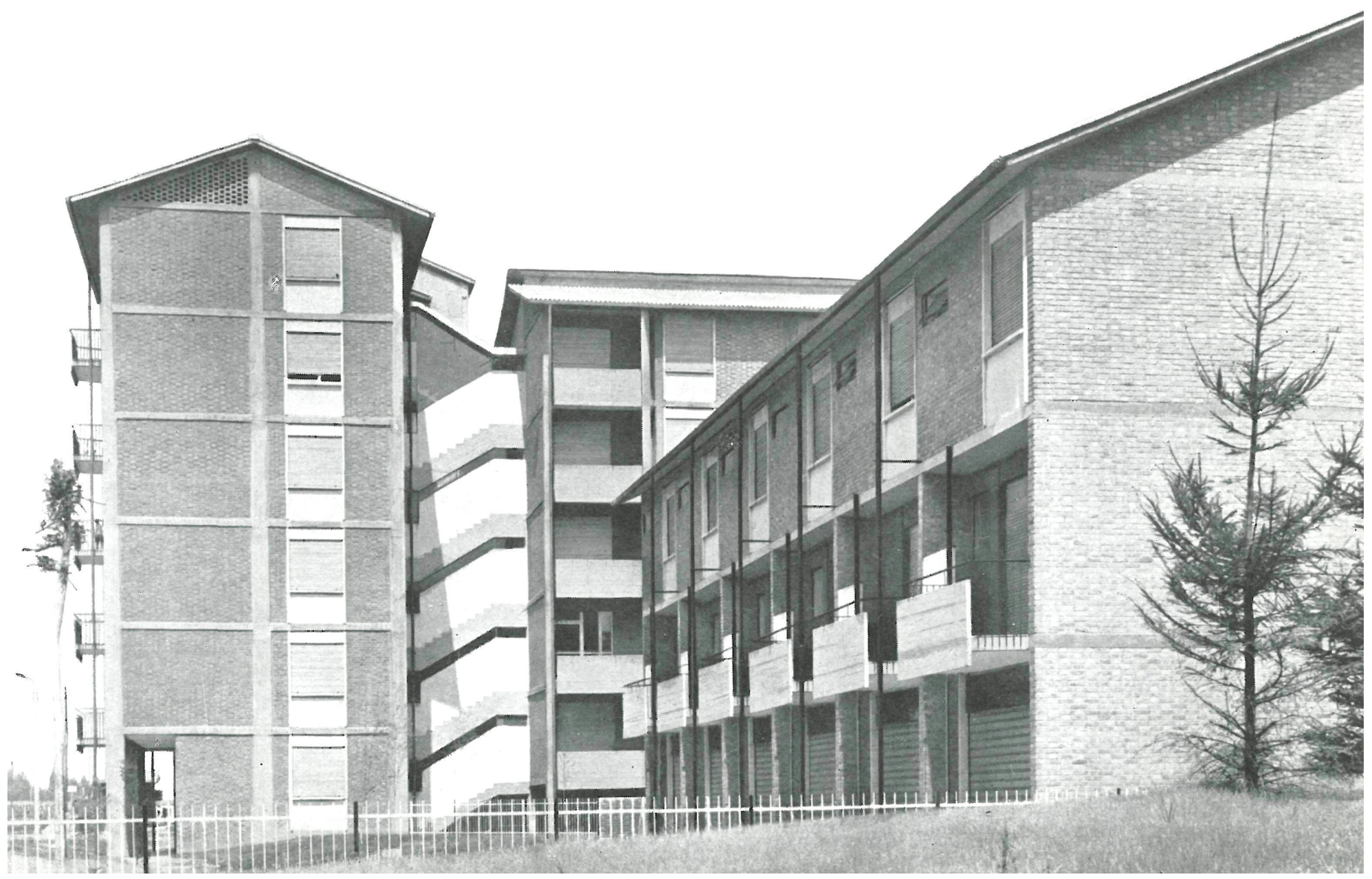



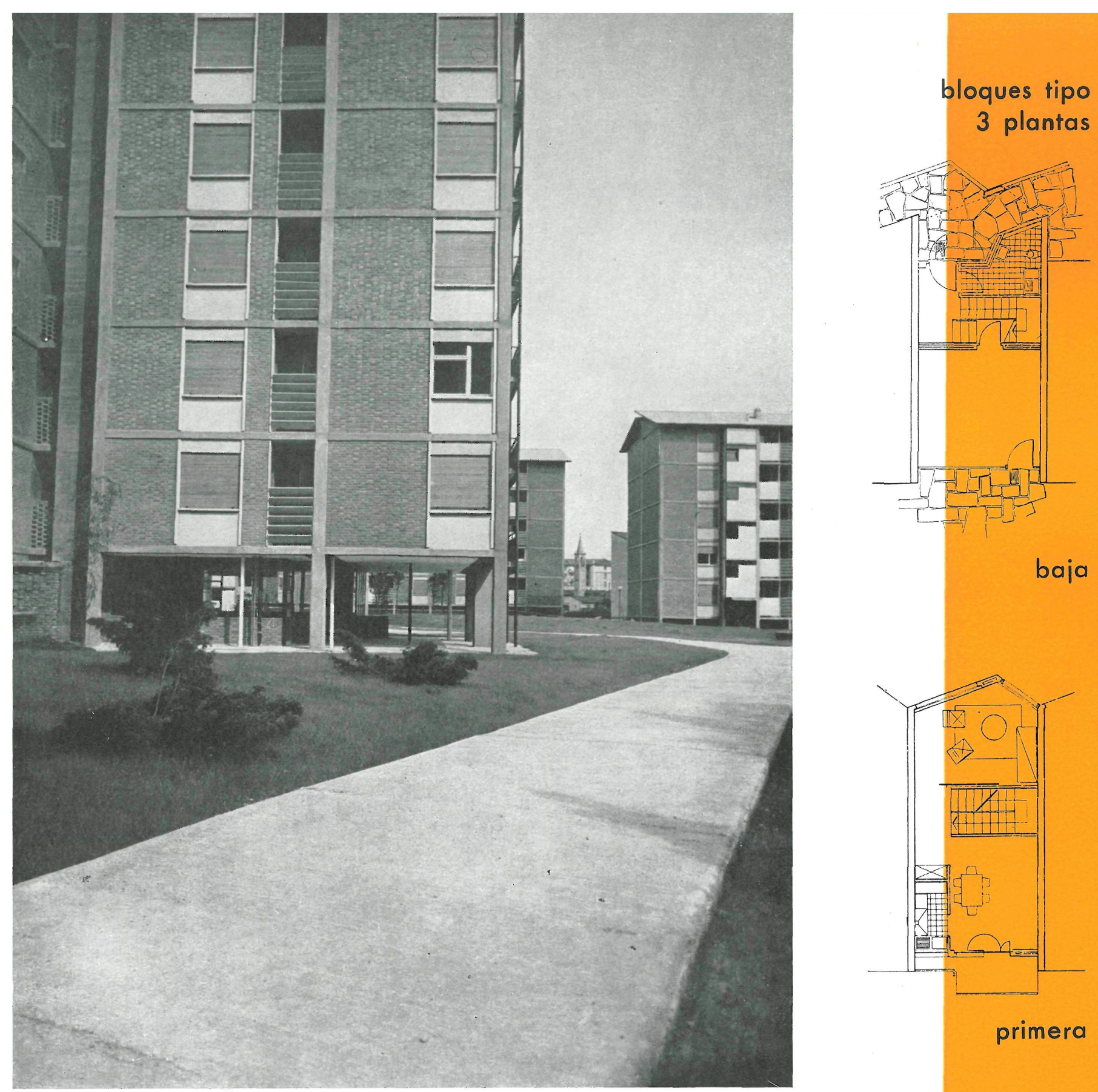

3 plantas 


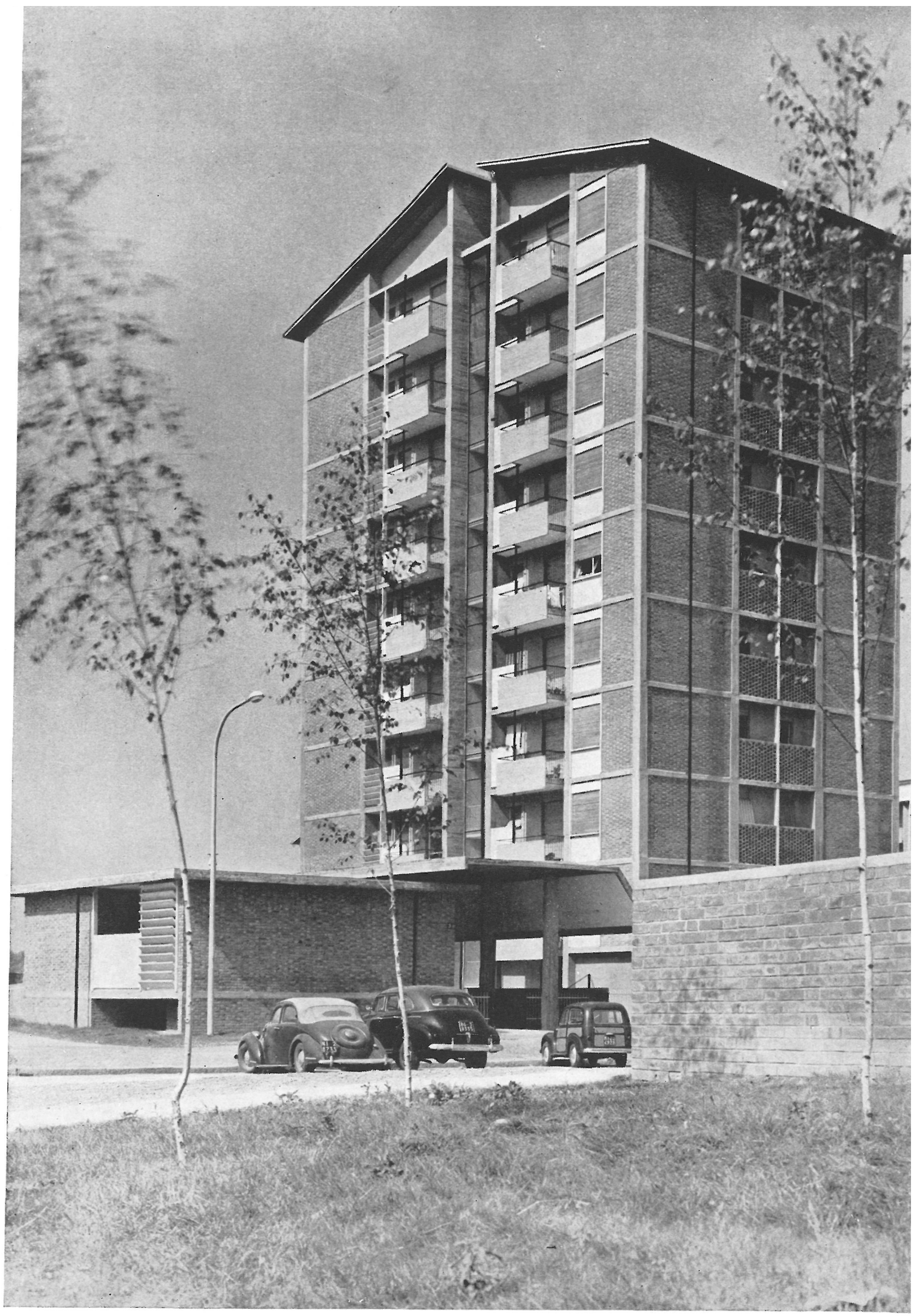

Fotos: ALDO BALLO 

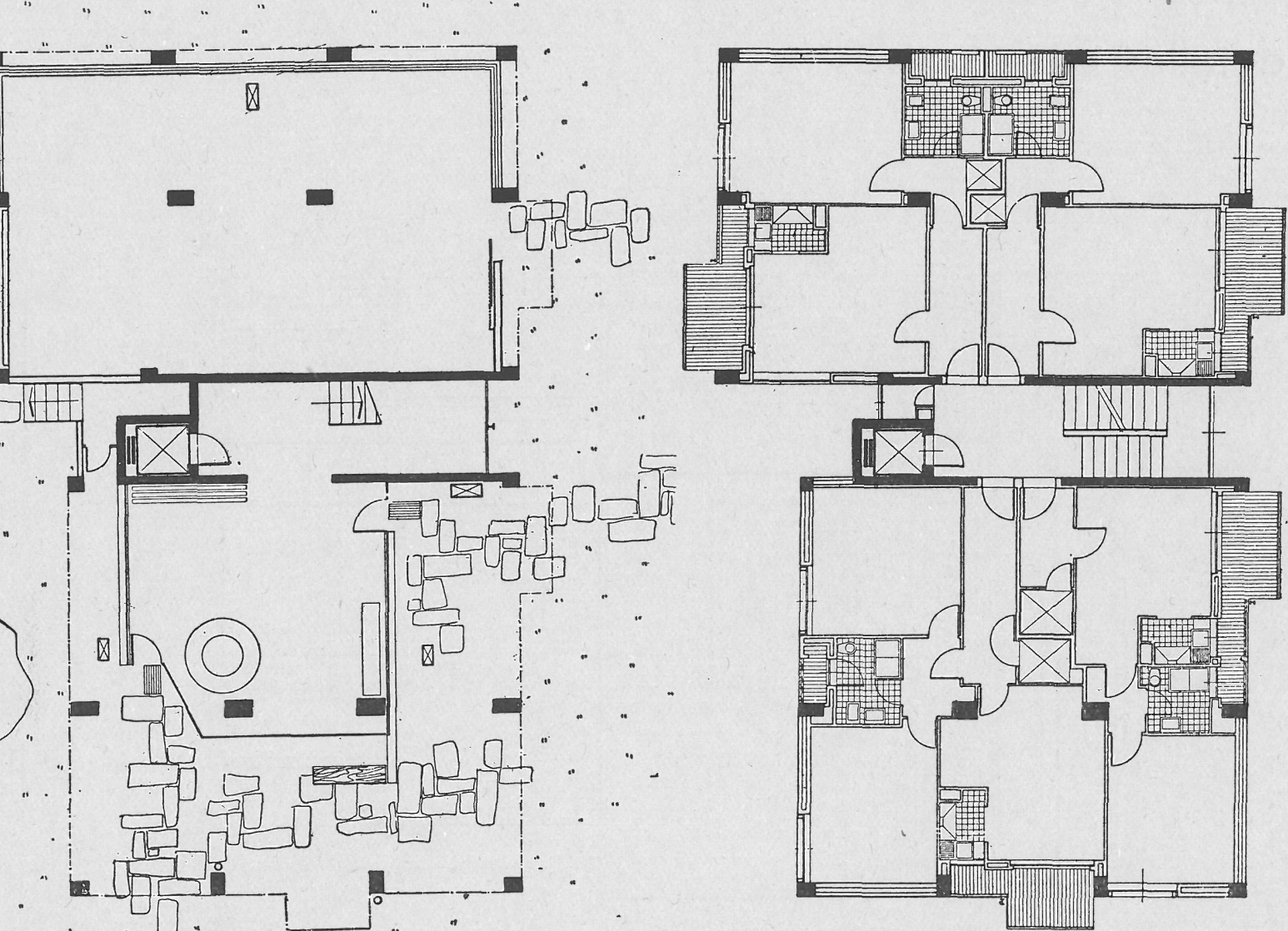

b a ja

El principal interés de este trabajo de Gandolfi consiste en la interpretación que ha dado a la idea del distrito, abandonando el esquema volumétrico que caracteriza en gran parte a la edificación popular; y al mismo tiempo ha evitado el atrayente diseño desarticulado y retorcido que suele planearse en estos últimos años.

Aquí "la unidad" ha sido asumida como norma fundamental para regir la simple composición de los volúmenes, que adquieren fuerza expresiva propia en el conjunto.

El carácter que resulta es decididamente actual, tanto en el tratamiento de los materiales (hormigón armado visto y fábrica de ladrillo), como en el método de construcción (por elementos unificados y prefabricados para todos los bloques de ventana y para los antepechos). $Y$, además, se ha revelado otro punto de especial interés, consistente en un inconfundible carácter de esta arquitectura, dada por el modo especial en el uso de los muros de ladrillo tratados a cara vista.

La unificación de los elementos constructivos, además de las puras soluciones técnicas, encuentran su raíz conceptual en la modulación que rigen los trazados de los diferentes tipos de alojamientos, en los cuales los elementos de servicio (cocina, baño) y los accesorios (balconcitos de servicio y balcones de estancia) son constantes en todo el distrito.

Las casas alineadas se distinguen por estar elevadas del terreno sobre pórticos continuos, que corresponden a locales vacíos, mientras las casas de torre tienen una planta baja con atrio vidriado, útil ambiente de vida para los niños y para los adultos.

Un controlado uso del color, en los fondos de las terrazas y en los elementos de hierro, reaviva el conjunto y aporta interés al diseño de los varios proyectos, poniendo de relieve los elementos lineales de la construcción. 


\section{detalles constructivos}
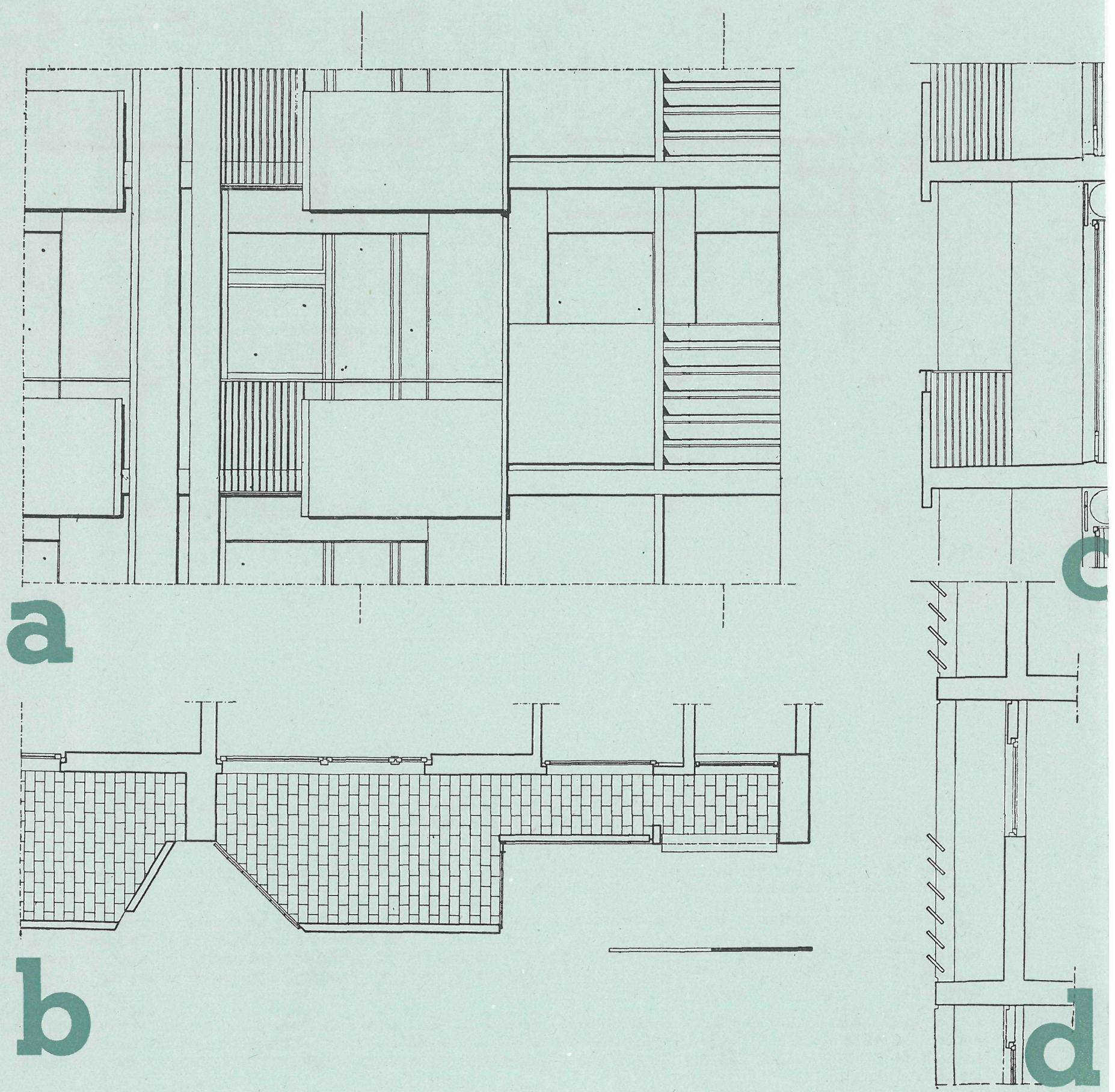

Fachada, terrazas y balcones.
a. Alzado
b. Planta.
c. Sección por balcón.
d. Sección por celosía. 